\title{
MODELOS FÍSICOS DE FALHAS DE EMPURRÃO COM TRAJETÓRIA EM DEGRAU
}

\author{
CAROLINE JANETTE SOUZA GOMES*, JULIANO EFIGENIO FERREIRA** \& MILTON PEREIRA FILHO***
}

\begin{abstract}
PHYSICAL MODELS OF THRUST FAULTS WITH STAIRCASE TRAJECTORY This work aims to describe the results of physical experiments on the propagation of staircase thrusts. Kinetic and geometric features of these thrust faults have been largely simulated in sandbox experiments and computer modeling in which the hanging-wall flat has been positioned on the layers, which are situated at the model top. The models employed in the present studies follow the theoretical assumptions and put the hanging-wall flat into an interlayered incompetent rock bed. Several boundary conditions were applied to eight physical experiments, and the influence that these conditions had in the propagation of the thrust faults was analyzed. Such conditions include: l- Different lengths for the initial model of each experiment to modify the internai stress in the sand prism; 2 - A sheet of sand paper placed at the base of some models, allowing to study the role of basal friction; 3 A wooden wedge in the foreland of the model to induce the creation of a frontal ramp, this is the leading thrust of the fault system; 4- A fixed wall to simulate a physical obstacle in the foreland. The physical experiments have demonstrated that the nucleation of a non-outcropping thrust with a staircase geometry requires a high sliding friction coefficient, which temporarily interrupts the progressive faulting in the forward-breaking sequence. The progressive shortening is thus transferred to the incompetent stratum that has low sliding friction coefficient and lies between competent layers. In sandboxes, the formation of a staircase thrust as defined above is ruled by a criticai relationship between friction coefficients of both the basal detachment and the incompetent bed. High friction coefficient at the detachment is explained by the water content depletion along the fault plane as a consequence of fluid pressure variations.
\end{abstract}

Keywords: piggy-back thrust sequence; coefficient of sliding friction; incompetent layer; fluid pressure.

RESUMO $O$ presente trabalho descreve a formação de falhas de empurrão com trajetória em degrau, em caixas de areia. As feições cinemáticas e geométricas das falhas em degrau tem sido largamente descritas através de simulações físicas e numéricas. Entretanto, nos estudos até agora realizados, ao invés de se posicionar o segundo patamar da falha no interior do pacote rochoso, ao longo de uma camada incompetente conforme previsto no modelo teórico, este se desenvolve no topo do modelo. Em oito experimentos foram modificados o comprimento inicial do modelo, a presença de papel lixa sobre o descolamento basal e a existência de um 'obstáculo' no antepaís, uma cunha rígida ou a própria parede frontal fixa da caixa de experimentos. O estudo demonstrou que uma falha de empurrão adquire geometria em degrau, com patamar não aflorante, quando a resistência ao movimento progressivo, causada por um alto coeficiente de atrito basal, interrompe (temporariamente) o processo normal de falhamento por colapso da lapa. O deslocamento progressivo é transferido para uma camada incompetente intercalada entre dois pacotes competentes, em detrimento à superfície de topo do pacote, quando o coeficiente de atrito da camada incompetente for baixo. Observou-se que a formacão da falha de empurrão com geometria em degrau e patamar não aflorante é governada por uma relacão crítica entre os coeficientes de atrito do descolamento e da camada incompetente. Para valores elevados do coeficiente de atrito ao longo da falha mestra assume-se, na natureza, um decréscimo na pressão dos fluidos, normalmente alta, resultante de uma variação no volume de fluidos no protótipo.

Palavras-chave: falhamento por colapso da lapa; coeficiente de atrito basal; camada incompetente; pressão dos fluidos.

INTRODUÇ̃̃O A relação genética entre falhas e dobras em cinturões de cavalgamentos têm sido reconhecida desde o trabalho pioneiro de Rich (1934), nos Pine Mountains, na porção sul do cinturão de dobras e falhas dos Apalaches, nos Estados Unidos. Segundo o autor as grandes estruturas anticlinais do cinturão teriam se formado pelo movimento translacional de lascas de empurrão sobre falhas com trajetória em degrau, de rampas e patamares, com flexão progressiva do teto da falha, na região da rampa.

Desde então, o conceito das falhas em degrau foi amplamente aceito e aplicado a cinturões de dobras e falhas no mundo inteiro e tem sido especialmente bem aceito para a interpretacão de dados estruturais de subsuperfície, produzidos a partir de perfis sísmicos. Suppe (1983) desenvolve um modelo cinemático e geométrico para os fault-bend folds (Fig. 1) que constituiu a chave para o balanceamento de perfis, primeiramente descrito por Dahlstrom (1969).

A partir da década de oitenta, um número muito grande de autores tem estudado os cinturões de cavalgamentos, levantando questões pertinentes às suas feições geométricas, mecânicas e cinemáticas. Cooper et al. (1983), Chapman \& Williams (1984), Evans (1989), Alvarez-Marron (1995), entre outros, aplicam o modelo dos fault-bend folds ao balanceamento estrutural com excelentes resultados, do ponto de vista geométrico. Shaw et al. (1994), com base na teoria dos fault-bend folds (Suppe 1983), desenvolvem uma técnica de mapeamento das superficies axiais de dobras angulares do tipo kink para a análise tridimensional de dobras-falhas. Os autores prevêem a geometria da falha e o seu rejeito a partir da forma da dobra e vice-versa. Obtêm estruturas perfeitamente balanceadas, mas não se preocupam com a mecânica das rochas.

Nos anos recentes têm sido desenvolvidas modelagens numéricas para auxiliar no entendimento do campo das tensões atuantes durante a geração das estruturas em anticlinal sobre superficies de falhas (Johnson \& Berger 1989, Byme et al. 1993, Erickson \& Jamison 1995 etc.). Modelos fisicos, com areia, foram empregados para a investigacão de cinemática e mecânica envolvidas no processo deformacional (Marshak \& Wilkerson 1992, Mulugeta \& Koyi 1992, Storti et al. 1997 etc.). Para a análise da mecânica dos sistemas compressivos, outros autores, tais como Dixon \& Liu (1991), Dixon \& Tirrul (1991) e Liu
\& Dixon (1991), realizaram experimentos físicos em uma centrífuga (Experimental Tectonics Laboratory, Queen's University, Kingston, Ontário) utilizando finas camadas de plasticina e silicone, em variadas proporções.

A sequência temporal entre a formação das falhas e dobras tem gerado controvérsias por longos anos. Thorbjomsen \& Dunne (1997) reconhecem tanto um mecanismo que se inicia com a geração do falhamento seguindo-se o dobramento, quanto o processo inverso. Os autores ampliam os três modelos cinemáticos de dobras-falhas, originalmente propostos por Jamison (1987), para cinco modelos: 1) Breakthrust fold; 2) Fault-propagation fold; 3) Detachment fold; 4) Faultbend fold; 5) Fault-arrest fold (Fig. 2).

Marshak \& Wilkerson (1992) e Mulugeta \& Koyi (1992) descreveram, a partir de experimentos físicos em um sistema acamadado comumente utilizado nos modelos com areia (designado também como, 'pacote' de areia), a formação de um sistema de falhas e dobras. Segundo os autores, a deformacão se inicia com um encurtamento paralelo às camadas (layer-parallel shortening) o que é reconhecido, no experimento, pelo espessamento do pacote de areia na frente da parede móvel (do backstop, segundo Byrne et al. 1993) da caixa de experimentos. O processo prossegue com o deslocamento do domínio espessado sobre o descolamento basal, e, com o encurtamento progressivo, desenvolve-se uma dobra anticlinal do tipo kink. $\mathrm{O}$ flanco curto desta dobra é rompido gerando uma rampa de empurrão, que une o descolamento basal ao topo da camada mais nova do sistema acamadado, de areia. $\mathrm{O}$ movimento subsequente da estrutura em anticlinal, sobre a rampa da falha de empurrão, é pequeno. Ocorre novo espessamento no antepaís, formação de nova dobra anticlinal e o processo se repete enquanto a deformação persiste.

Após investigação experimental minuciosa, Storti et al. (1997) puderam caracterizar que fault-bend folds se formam obedecendo a uma sequência de quatro etapas de deformação, começando com o encurtamento paralelo às camadas e prosseguindo com a geração de um detachment fold que, por sua vez, evolui para um thrust-tipfold e, finalmente, para um thrust-ramp fold.

Em todos os experimentos físicos que se ocuparam com a geração de falhas de empurrão com trajetória de patamar-rampa-patamar, $\mathrm{o}$

* Departamento de Geologia, Escola de Minas, Universidade Federal de Ouro Preto, Morro do Cruzeiro, s/n., 35.400-000 Ouro Preto - Minas Gerais,Fax: (031) 559 1605,E-mail: caroline@degeo.ufop.br.

** Bolsista Iniciação Científica: PIC / CNPq/UFOP, Departamento de Geologia, Escola de Minas, Universidade Federal de Ouro Preto, Morro do Cruzeiro, $\mathrm{s} / \mathrm{n}$., 35.400-000 Ouro Preto - Minas Gerais - Brasil

*** Bolsista Iniciação Científica: FAPEMIG, Departamento de Geologia, Escola de Minas, Universidade Federal de Ouro Preto - Morro do Cruzeiro, s/n., 35.400-000 Ouro Preto - Minas Gerais - Brasil 

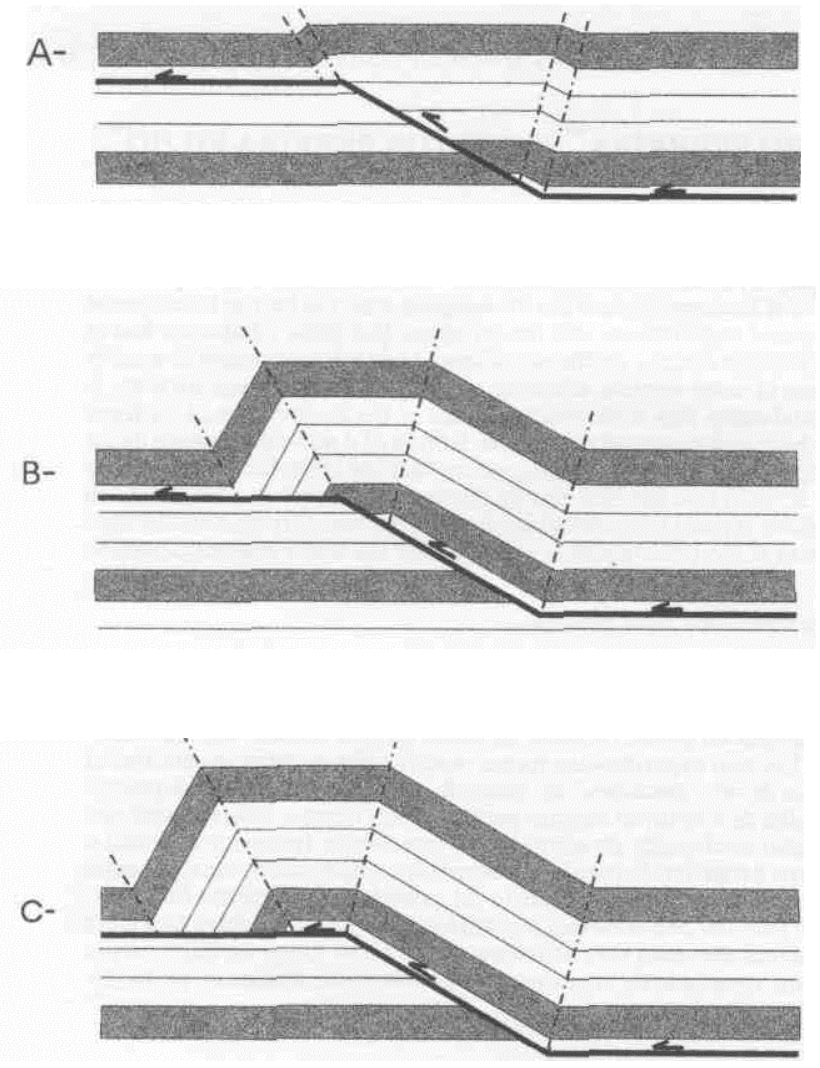

Figura $l$ - (A), (B) e (C) mostram a evolução progressiva de um fault-bend fold, idealizado por Suppe (1983), onde o bloco do teto da falha é flexionado a medida que este é empurrado ao degrau superior da falha (modificado de Suppe 1983).

segundo patamar da falha se forma no topo da camada mais nova do sistema acamadado. No presente trabalho apresentam-se os resultados de novas modelagens físicas, que foram realizadas no intuito de investigar a evolução de falhas em degrau cujo segundo patamar se forma no interior do pacote (uma 'falha em degrau não aflorante') associado a um dobramento do teto da falha. Por simular novas situações, os experimentos permitem avançar no conhecimento da propagação de sistemas de empurrões.

Nos experimentos realizados assumiu-se, como tese de trabalho, que falhas com trajetória em degrau não-aflorantes se formem em consequência a uma interrupção forçada, no processo de falhamento, em estilo propagação por colapso da lapa (forward-breaking sequence). Este pressuposto surgiu da análise dos trabalhos desenvolvidos por Huiqi et al. (1992) que simularam um processo de falhamento, em estilo propagação por colapso da lapa, em modelos de areia. Os autores demonstraram que sistemas compressivos em cinturões de dobras e falhas e em prismas de acresção se desenvolvem progressivamente, no antepaís, em um processo que somente termina quando o pacote acamadado de areia se torna estável, isto é quando o pacote desliza sobre o descolamento basal sem mais nenhuma deformação interna.

Adotou-se, nos experimentos, a concepção teórica de Suppe (1983) que preconiza para a formação do segundo patamar da falha, a presença de uma camada incompetente no interior do pacote em deformação. Esta, devido ao seu baixo coeficiente de atrito basal, induziria o bloco do teto do empurrão a se deslocar sobre a mesma, na horizontal, ao invés de se propagar até o topo.

Nos modelos, testaram-se sucessivamente novas condições de contorno (boundary conditions) visando: a) uma interrupção no processo de falhamento em estilo propagação por colapso da lapa e b) o deslizamento do teto da falha sobre um segmento horizontal. Tais condições foram atingidas com a introdução de papel lixa no fundo da caixa que elevou o coeficiente de atrito basal e com a intercalação de uma camada de cristais de mica no interior do pacote de areia.

Os presentes experimentos não tinham o objetivo de simular uma determinada situação geológica nem discutir as teorias modernas sobre a geração de cadeias montanhosas (por exemplo, Godin et al. 1999).
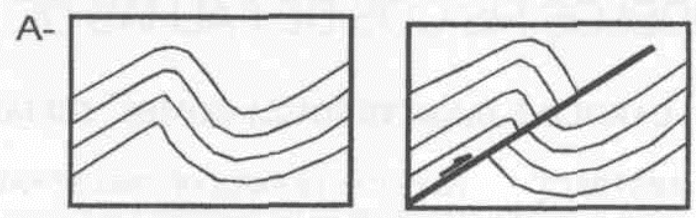

B-
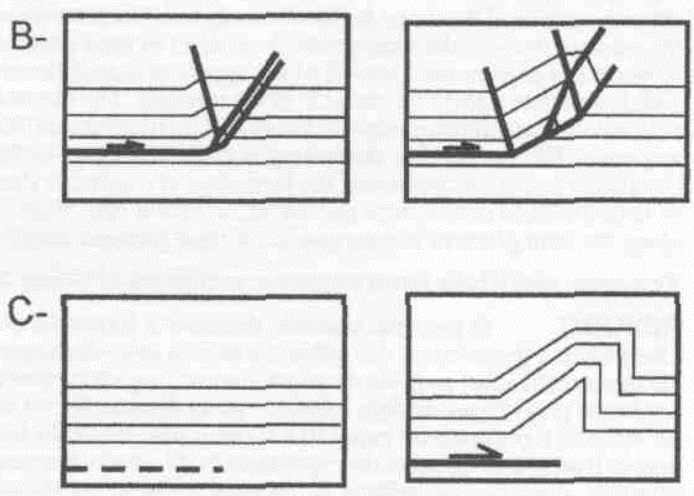

D-
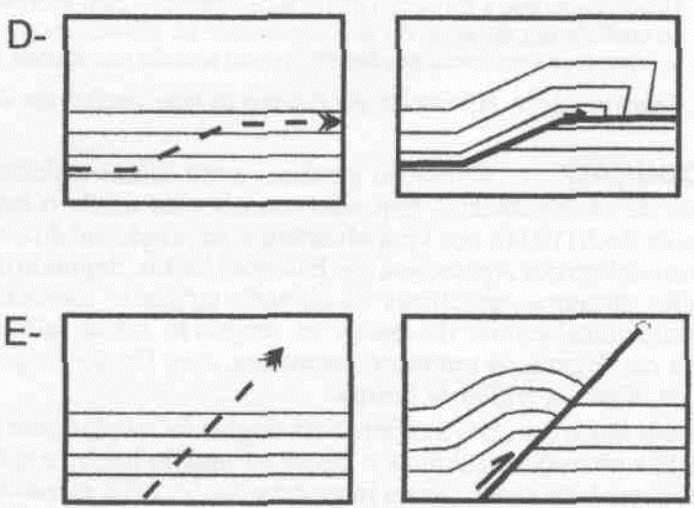

Figura 2 - Desenhos esquemáticos mostrando a evolução de dobrasfalhas, segundo Thorbjornsen \& Dunne (1997): A) Break-thrust fold; B) Fault-propagation fold; C) Detachment fold; D) Fault-bend fold; E) Fault-arrest fold.

Pretendia-se apenas contribuir para o conhecimento da cinemática de falhas com trajetória em degrau, estruturas extremamente comuns na natureza. Para tal, adotou-se o modelo clássico da formação de cinturões de dobras e falhas pelo processo de upthrusting. O trabalho constitui parte de uma pesquisa sobre mecanismos de deformação de sistemas compressivos e transpressivos, o qual gerou, entre outros, um estudo sobre a formação de pilhas antiformais (Gomes \& Ferreira 2000). O interesse pelas falhas com trajetória em degrau nasceu de um estudo sobre o Sistema de Cavalgamento Fundão-Cambotas, um cinturão de dobras e falhas, brasiliano, na região leste do Quadrilátero Ferrífero, no Estado de Minas Gerais. O cinturão foi alvo de inúmeras pesquisas geológicas (Dorr 1969, Chemale Jr. et al. 1991, Alkmim \& Marshak 1998 etc.) sendo interpretado como um complexo sistema imbricado de falhas que se conecta em profundidade. A ausência de dados do inventário estrutural em profundidade impede a comprovação dos modelos tectônicos, no entanto, os experimentos físicos representam um instrumento de reconstituição e visualização da geometria das estruturas. Assim, presente modelagem tectônica pretende contribuir para o conhecimento da cinemática de sistemas compressivos em geral e, em especial, para aquele do Sistema de Cavalgamento Fundão-Cambotas, no Quadrilátero Ferrífero (Gomes et al. 2000).

A MODELAGEM FÍSICA A modelagem física analógica tem como objetivo construir modelos 'que sejam tão próximos quanto possível aos seus equivalentes naturais'. Hubbert (1937) escreve um 
trabalho clássico sobre a teoria da similaridade, no qual demonstra porque, nos experimentos, é permitido o uso de materiais equivalentes aos da natureza, que são deformados sob tensão e tempo menores e em velocidade maior, em relação ao que ocorre na natureza.

Como os experimentos realizados pretendem simular a geração de falhas de empurrão na crosta superior, onde os materiais rochosos normalmente apresentam comportamento rúptil, é necessário o controle sobre os coeficientes de similaridade de tensão e distância. Segundo a lei de Hooke (Handin 1966), os materiais elásticos são caracterizados por apresentarem uma relação linear entre a tensão cisalhante $(\Delta \sigma)$ e a deformação longitudinal $(\Delta 1)$, expressa por $(\Delta \sigma)=\mathrm{k}(\Delta 1),(2)$

onde $\mathrm{k}$ é uma constante (o módulo de Young) que depende do material e das condições externas. Na comparação (modelo) $\mathrm{m} /$ (original $)_{0}$ esta relação é rescrita com os fatores de similaridade:

$\sigma_{\mathrm{r}}=(\delta)(\lambda),(2)$

onde

$\sigma_{\mathrm{r}}=(\Delta \sigma)_{\mathrm{m}} /(\Delta \sigma)_{0}, 0$ que corresponde a (coesão) $)_{\mathrm{m}} /(\text { coesão })_{0},(3)$

$\delta=($ densidade $) \mathrm{m} /(\text { densidade })_{0}(4)$

$\mathrm{e}$

$\lambda=($ distância $) \mathrm{m} /$ (distância) $)_{0}$. (5)

A equação (2) demonstra que, se no mdelo diminuirmos a distância entre dois pontos por um fator de escala $\lambda=10^{\text {" }}$ temos que diminuir 0 seu coeficiente de coesão $\sigma_{\mathrm{r}}$, também por $10^{-5}$, uma vez que, por se manter constante em qualquer distancia, a densidade dos materiais muito pouco influencia no resultado da equação.

O uso da areia, como material analógico, é balizado pela equação (2) acima, pois, o fator de escala $\lambda=10^{-5}(1 \mathrm{~cm}=1 \mathrm{~km})$, comumente utilizado, acarreta uma redução na coesão do material analógico, $\mathrm{a}_{\mathrm{r}}$, também por $10^{-5}$ (ou 100.000 vezes). Uma redução de 100.000 vezes na coesão da rocha natural resulta para o material analógico, em uma coesão próxima a zero. Este é o caso da areia seca (McClay \& Ellis 1987).

A areia de quartzo rompe de acordo com o critério de CoulombMohr, independe da taxa de deformação (strain rate) e possui baixa coesão e ângulo de atrito interno de $30^{\circ}$ (Vendeville et al. 1987 , McClay \& Ellis 1987). Nos presentes experimentos utiliza-se areia peneirada, na granulometria de $200 \mu \mathrm{m}$ a $300 \mu \mathrm{m}$, e tingida. A areia é tingida em diferentes cores com a finalidade de permitir uma melhor visualização de camadas e estruturas.

Nos experimentos físicos utilizou-se como material analógico, além da areia tingida, mica em cristais do tamanho de grãos de arroz. Segundo McClay \& Scott (1991), a mica quando disposta paralelamente às camadas de areia possui coesão próxima a zero e produz uma anisotropia que favorece o deslizamento entre as camadas em detrimento ao falhamento. Em presentes modelos, cristais de mica foram empregados na forma de horizontes intercalados no sistema acamadado de areia para induzir ao deslizamento interestratal e como camadas mais espessas (de 0,5 e de $1,0 \mathrm{~cm}$ ) no interior do pacote de areia (Fig. 3), simulando uma litologia incompetente (por exemplo, xisto/filho entre camadas de quartzitos ou argilito/folhelho entre camadas de arenito/calcário).

MÉTODO DE TRABALHO Os experimentos foram realizados em caixas de acrílico incolor, de 20,60 e $10 \mathrm{~cm}$ de largura, comprimento e altura, respectivamente. As paredes laterais transparentes permitiram a observação direta dos efeitos da deformação em cada etapa do processo deformacional. A parede frontal móvel deslocavase, a uma velocidade constante de $2 \mathrm{~cm} / \mathrm{h}$, em direção à parede frontal fixa, conforme indicado pela seta horizontal na figura 3.0 movimento da parede frontal móvel foi gerado pela ação de um motor acoplado (não mostrado na figura 3), permitindo que as camadas de material analó gico (areia e mica) se deformassem progressivamente.

Ao final de cada modelagem a areia foi umedecida e, em uma segunda etapa de trabalho, efetuaram-se cortes nos experimentos, na direção do transporte tectônico, distantes pelo menos $2 \mathrm{~cm}$ das paredes laterais, para eliminar o efeito do atrito sobre as estruturas geradas.

A documentação dos experimentos, através de fotografias, foi realizada durante as duas etapas de trabalho, em intervalos regulares, durante o processo deformativo e após deformação e umedecimento do modelo, nos cortes internos. As fotografias, que ilustram o presente trabalho, visaram mostrar a deformação progressiva da primeira etapa de trabalho. Todas as fotografias com exceção daquela da figura 11 foram obtidas através do vidro incolor e transparente. A figura 11 representa uma seção central do modelo FBF-2b que, comparada à figura 10D (o mesmo modelo sob mesmo encurtamento), revela a principal diferença entre os dois perfis: os traços das estruturas rúpteis são mais nítidos na seção central. Como, no entanto, este fator não influencia a análise geral dos experimentos, as fotos obtidas através do vidro foram utilizadas, normalmente, na interpretação das modelagens.

Todos os experimentos foram repetidos várias vezes para a confirmação dos resultados.

Em todos os experimentos empregou-se uma mesma 'coluna estratigráfica' para o sistema acamadado com variacões apenas no número de camadas de areia. Conforme figura 3 (modelo FBF-la) utilizaramse dois pacotes de areia em cada experimento, um basal, de areia pura (o 'pacote basal'), que pretendia simular a deformação rúptil, e outro de topo, de areia intercalada por horizontes de cristais de mica (o 'pacote de topo'), cujo objetivo era gerar uma deformação do tipo deslizamento interestratal. Entre os dois pacotes de areia introduziu-se uma camada incompetente de cristais de mica. A função desta camada era induzir a um movimento entre os pacotes basal e de topo, ambos competentes, e, com a deformação progressiva, à formação de um segmento horizontal na trajetória da falha.

Desenvolveram-se duas sequências de experimentos, FBF-1 e FBF-2, que se diferenciavam entre si basicamente pela presença de uma cunha de madeira no antepaís, em FBF-2 (Fig. 3). O papel da cunha de madeira, nos experimentos, era causar a interrupç̃o do processo de falhamento em estilo propagação por colapso da lapa e criar condições favoráveis à ascensão e ao deslizamento do teto da falha sobre uma superficie com geometria em degrau.

Cada uma das duas sequências, FBF-1 e FBF-2, foi estudada em quatro séries $(\mathrm{a}-\mathrm{d})$ (Fig. 3), nos quais se alteraram: i) a espessura da camada de cristais de mica, intermediária (de 1,$0 ; 0,5$ ou $0,1 \mathrm{~cm})$, ii) o comprimento dos modelos (de 40, 30, 25 ou $15 \mathrm{~cm}$ ) (que modífica o estado de tensão) e iii) a introdução de papel lixa no modelo. O papel lixa cobre toda a base da caixa nos modelos FBF-1 c e 1 d e FBF-2c e $2 \mathrm{~d}$ ou apenas a metade da base, no domínio mais afastada da parede móvel (no antepaís) (FBF-lb e FBF-2b). A introducão do papel lixa nos modelos tinha o intuito de aumentar o coeficiente de atrito dinâmico sobre o descolamento basal, que diz respeito às propriedades friccionais na superficie da falha após iniciado o deslizamento entre os blocos (Ranalli 1987). Pretendia-se minimizar o movimento do sistema acamadado sobre o descolamento basal favorecendo-se, desta maneira, o movimento do sistema sobre uma rampa de empurrão, em detrimento à formação de novas falhas, no antepaís.

Nos experimentos da sequência FBF-2, modelo FBF-2d, investigou-se ainda a influência do ângulo de mergulho da rampa de empurrão sobre a dobra de arrasto que se desenvolve no bloco do teto da falha.

As pequenas diferenças na altura dos modelos decorrem da variação na espessura da camada de mica (de 1,0,0,5 e 0,1 cm).

Com exceção do experimento FBF-la, os modelos não encostam na parede fixa da caixa do experimento. Esta parede representaria na natureza um alto estrutural do tipo maciço do embasamento que bloquearia o movimento contínuo da frente de empurrão. Em todos os outros experimentos, viabilizou-se o livre deslocamento do sistema acamadado sobre o descolamento basal e sobre a cunha de madeira simulando-se a situação mais comumente encontrada em cinturões de dobras e falhas ou em prismas de acresção.

\section{DESCRIÇÃO DOS EXPERIMENTOS Modelo FBF-1a No}

modelo FBF-la (Fig. 4) mostram-se dobras e falhas que se formaram em um processo de propagação por colapso da lapa. A deformação contínua, não apresentada nas fotos, gerou inicialmente um espessamento do sistema acamadado, na frente da parede móvel. $\mathrm{O}$ espessamento produziu uma dobra em caixa, com duas superfícies de charneira que se transformaram progressivamente em empurrão e retroempurrão. A foto da figura $4 \mathrm{~B}$ revela a dobra em caixa associada a uma falha de empurrão após $10 \%$ (4 cm) de encurtamento. Mais duas falhas, também associadas a dobras, se formaram após 30\% $(12 \mathrm{~cm})$ de compressão (Fig. 4C). Observa-se que a camada de mica se deformou plasticamente, com fluxo de material em direção às zonas de charneira das dobras, ao invés de falhar como a camada de areia. Este fato gerou nas falhas 1 da figura 4B e 1 e 2 da figura 4C uma refração no traço da falha.

Modelo FBF-1b No modelo FBF-lb, o sistema acamadado de areia não encosta na parede fixa da caixa de experimentos (comparar as figuras $4 \mathrm{~A}$ e $5 \mathrm{~A}$ ) que, em FBF-la impediu o deslocamento livre do antepaís. Em troca, cobriu-se a base da caixa do modelo (Fig. 5) com 


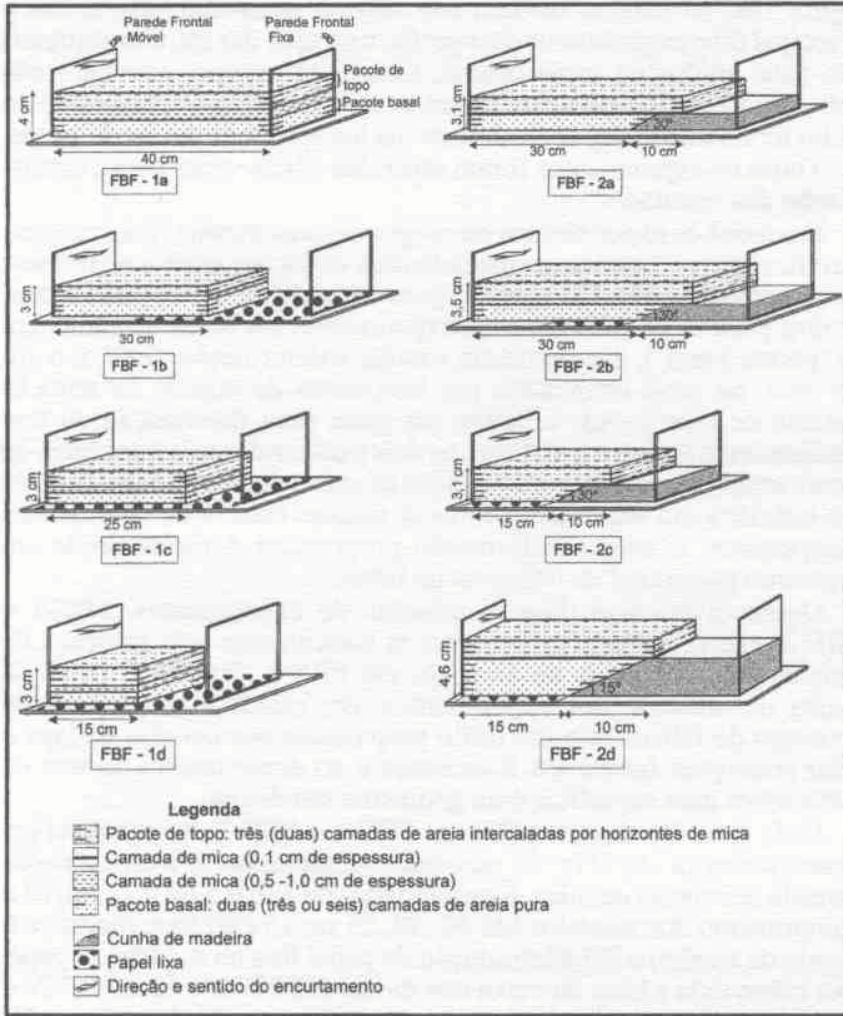

Figura 3 - Desenhos esquemáticos das sequências FBF-1 e FBF-2, com respectivas condições de contorno.

papel lixa na sua metade posterior distante da parede móvel. A deformação, neste modelo, se inicia da mesma forma como em FBF-1 a, com um espessamento do sistema acamadado e a formação de uma dobra em caixa com duas superficies de charneira que se transformam em um empurrão e um retroempurrão (não mostrado na figura 5). Na foto da figura 5B é apresentada a situação após $33 \%(10 \mathrm{~cm})$ de encurtamento: formaram-se quatro falhas de empurrão cujas rampas cortam até o topo do sistema acamadado. Observa-se nesta foto que, com a deformação progressiva, as falhas 1, 2 e 3 sofreram forte rotação anti-horária o que não ocorreu com a falha 4 , mais nova e menos deformada, cujo ângulo de mergulho se encontra próximo a $30^{\circ}$. A falha 4 mostra uma pequena refração no seu traçado pela mesma razão que causou este fato no modelo FBF-la. A elevada magnitude de deformação, de $66 \%(20 \mathrm{~cm})$ (Fig. 5C), causou o arrasto do bloco do teto da falha 4 ao longo da camada de mica (falha 5). Além disto, ocorreu o encurtamento das distâncias $\mathrm{D}_{1}$ e $\mathrm{D}_{2}$ para $\mathrm{D}_{1}{ }^{\prime}$ e $\mathrm{D}_{2}^{\prime}$ (vide Figs. 5B e 5C), produzindo a união de três dos quatro branch points (ou branch Unes, em 3D) (McClay 1992), e o prolongamento do descolamento basal em direção ao antepaís (falha 6). O pin-line que marca o final do experimento na figura $5 \mathrm{~B}$ revela na figura $5 \mathrm{C}$, o movimento de $2 \mathrm{~cm}$ de todo o sistema acamadado sobre a falha 6 (o descolamento basal) e um forte deslizamento do pacote de topo (de 4,5 $\mathrm{cm}$ ) sobre a falha 5 (no interior da camada de mica).

Presume-se neste experimento que, com a deformação contínua, a presença do papel lixa sobre a base do modelo causou um aumento na resistência ao movimento. Por esta razão ocorreu a junção dos branch points no pós-país do modelo tornando a camada de mica, de baixo coeficiente de atrito basal, ativa como plano de acomodação do encurtamento progressivo (falha 5)

A falha 5, na figura $5 \mathrm{C}$, representa o patamar de uma falha com 'falsa' trajetória em degrau. Esta trajetória é considerada 'falsa' posto que o referido patamar, na camada incompetente, se formou após a propagação inicial do empurrão (falha 4) até o topo.

Modelos FBF-1C e FBF-1d Nos modelos FBF-lc e FBF-ld (Figs. 6 e 7) uma folha de papel lixa cobre a base do experimento em

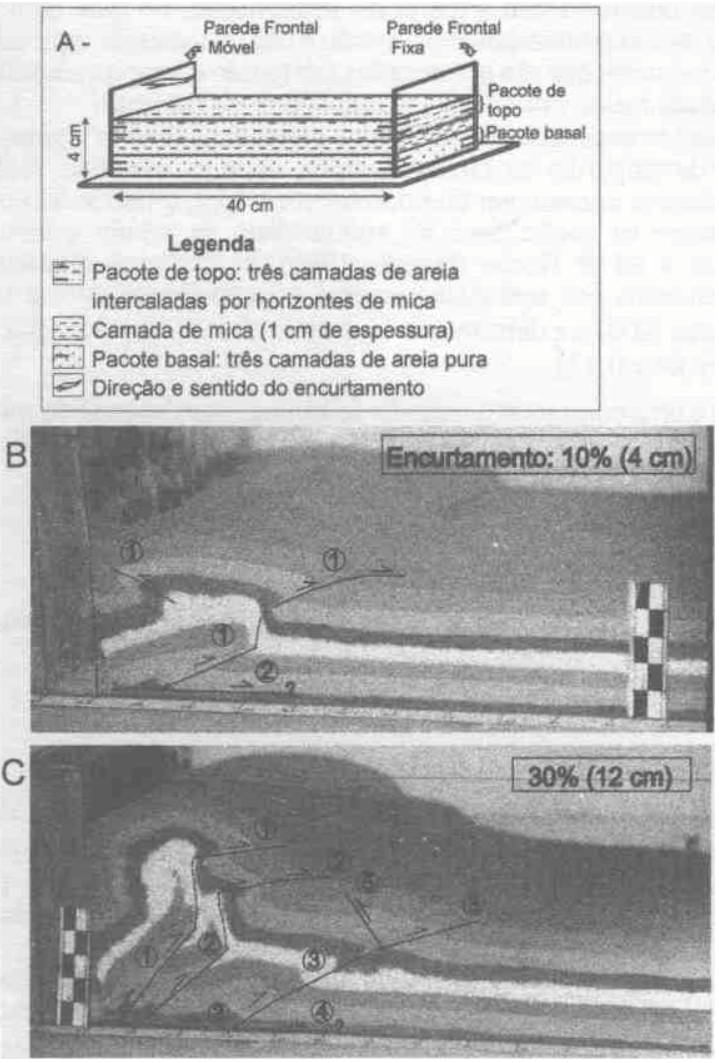

Figura 4 - (A) Desenho esquemático do modelo FBF-la com as condições de contorno. (B) and (C) Fotografias do modelo após $10 \%$ $(4 \mathrm{~cm})$ e $30 \%(12 \mathrm{~cm})$ de encurtamento, respectivamente. A escala lateral representa $5 \mathrm{~cm}$.

toda a sua extensão. Os dois modelos diferem entre si apenas pelo comprimento inicial, de 25 e $15 \mathrm{~cm}$ respectivamente.

No início da deformação, em estágio anterior ao mostrado nas figuras 6 e 7, deu-se a formação de uma estrutura com a geometria de uma dobra kink, próximo à parede móvel. Na figura $6 \mathrm{~B}$ é mostrado o encurtamento do modelo FBF-1 c após $16 \%(4 \mathrm{~cm})$, após o rompimento do flanco curto da dobra que forma a rampa de empurrão da falha 1 . É importante notar que esta falha não se propagou até o topo do sistema acamadado mas tem continuidade em um segmento horizontal, no interior da camada de mica. Nas fotos das fíguras $6 \mathrm{C}$ e $6 \mathrm{D}$, que apresentam a situação da deformação após $24 \%(6 \mathrm{~cm})$ e $48 \%(12 \mathrm{~cm})$ de encurtamento respectivamente, este fato se torna mais evidente devido ao deslizamento do teto da falha 1 ao longo da camada de mica (verificar a posição do pacote de topo em relação ao pin-line). A falha 1 é interpretada aqui como uma falha com trajetória em degrau. $\mathrm{Na}$ figura $6 \mathrm{D}$ é possível observar ainda que após $48 \%(12 \mathrm{~cm})$ de encurtamento (portanto, após a formação da falha com trajetória em degrau) um novo empurrão se formou no antepaís (falha 2) e, além disto, que todo o sistema acamadado se movimentou sobre o descolamento basal (falha 3).

A foto B da figura 7, do modelo FBF-ld, que apresenta o encurtamento após $27 \%(4 \mathrm{~cm})$, também ilustra a formação de uma falha com trajetória em degrau. Ambas as fotos da figura 7 (B e C) revelam o deslizamento progressivo do bloco do teto da falha 1 ao longo da camada incompetente, de mica. Na figura $7 \mathrm{C}$ que mostra o encurtamento de $40 \%(6 \mathrm{~cm})$ observa-se que, como no modelo anterior, FBF-lc (Fig. 6D), também neste experimento ocorreu o deslizamento de todo sistema acamadado sobre um descolamento basal após a formação da falha com trajetória em degrau.

A foto da figura 8 mostra uma falha em degrau, no detalhe, em um experimento que repetiu o modelo FBF-ld, de $15 \mathrm{~cm}$ de comprimento inicial. Neste experimento gerou-se um encurtamento maior, de $53 \%$ $(8 \mathrm{~cm})$, que produziu um aumento na amplitude da dobra de arrasto no bloco do teto da falha. 


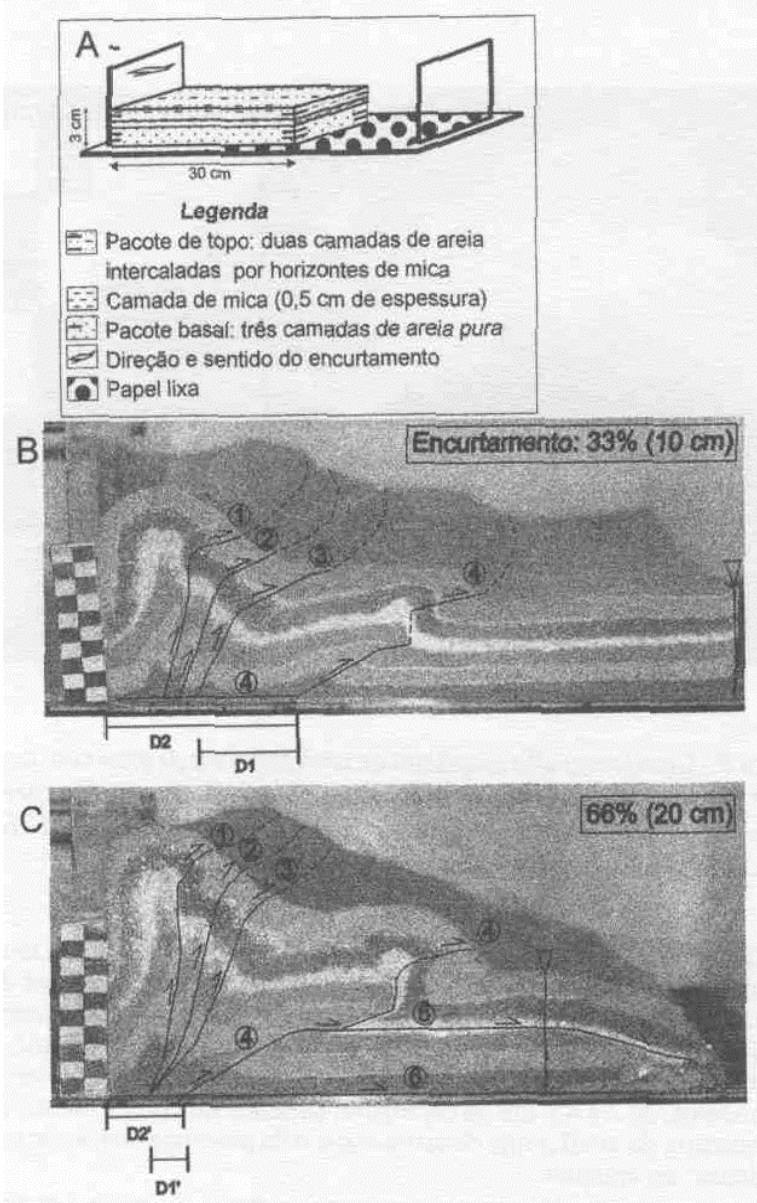

Figura 5 - (A) Desenho esquemático do modelo FBF-1b com as condições de contorno. (B) e (C) Fotografias do modelo após 33\% (10 $\mathrm{cm})$ e $66 \%(20 \mathrm{~cm})$ de encurtamento, respectivamente. Notar em (B) quatro empurrões que se propagam até o topo do pacote de areia e em (C) a formação de uma falha com 'falsa' trajetória em degrau. A escala lateral representa $5 \mathrm{~cm}$. O pin-line, nas fotografias, representa $o$ comprimento inicial do modelo. As distâncias Dl e D2 na figura (B) que foram reduzidas para D1'e D2' respectivamente, na figura (C), demonstram o encurtamento no pós-país do modelo. Em (C) observase, ainda, que o encurtamento foi acomodado essencialmente sobre a camada de mica (falha 5) e, em menor escala, sobre o descolamento basal (falha 6).

Modelo FBF-2a Nos modelos da sequência FBF-2 (Figs. 9, 10, 11, 12 e 13), com cunha de madeira rígida no antepaís, o deslocamento do sistema acamadado foi progressivamente bloqueado, causando forte arrasto dos pacotes basal e de topo sobre a rampa.

Em FBF-2a (Fig. 9B) registra-se, após 25\% (10 cm) de encurtamento, a formação de quatro falhas cada uma se iniciando no descolamento basal e se propagando até a superficie de topo do sistema acamadado através de rampas de empurrão (falhas 1, 2,3 e 4). Estágios posteriores, intermediários entre aqueles das figuras $9 \mathrm{~B}(25 \%$ de encurtamento) e $9 \mathrm{C}$ (50\% de encurtamento), não apresentados no trabalho, mostraram que na deformação progressiva as falhas 1,2 e 3 se aproximaram entre si até formarem branch points coincidentes e, então, cavalgaram a falha 4 . Ao mesmo tempo, o descolamento basal (a falha 5) se propagou até a cunha de madeira onde o bloco do teto foi forçado a subir a rampa e se estender até a superficie de topo do sistema acamadado. Na figura 9C observa-se o cavalgamento das falhas 1,2 e 3 sobre a falha 4 que se rompeu na altura da camada de mica, produzindo a falha 6 , horizontal. Esta, cortou a falha 5 , no antepaís, ao meio. A figura 9D (60\% de encurtamento) mostra que o encurtamento progressivo foi acomodado por forte deslizamento ao longo das falhas 6 e 5 .

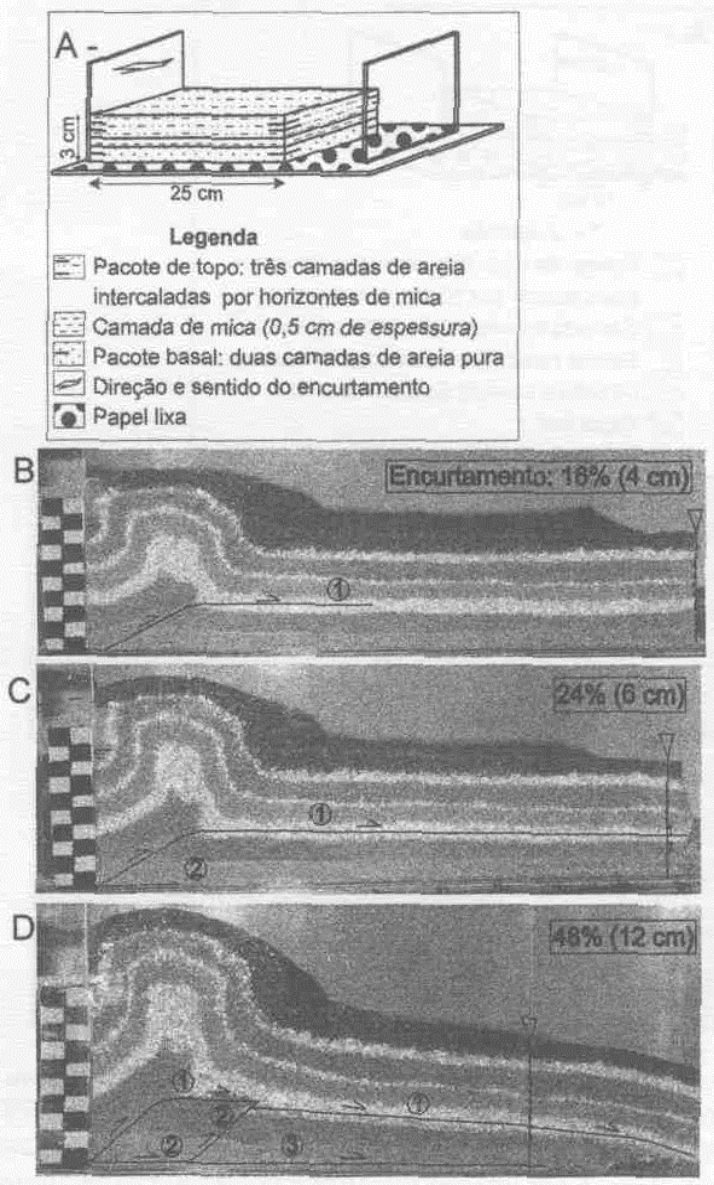

Figura 6 - (A) Desenho esquemático do modelo FBF-1c com as condições de contorno. (B), (C) e (D) Fotografias do modelo após $16 \%$ $(4 \mathrm{~cm}), 24 \%(6 \mathrm{~cm})$ e $48 \%(12 \mathrm{~cm})$ de encurtamento, respectivamente. A escala lateral representa $5 \mathrm{~cm}$. A pin-line nas fotografias representa o comprimento inicial do modelo.

A evolução das falhas, descrita acima, demonstra que a estrutura resultante (Fig. 9D) constitui novamente uma falha com 'falsa' trajetória em degrau: o primeiro patamar (o descolamento basal) e a rampa de empurrão são representadas pela falha 5 , que originalmente se propagou até o topo do sistema; o segundo patamar é constituído pela falha 6 , que se formou no pós-país e cortou a falha 5 , mais nova, no antepaís.

Modelo FBF-2b As condições de contorno dos modelos FBF-2a e 2 b (Figs. 9 e 10) diferem entre si pela espessura da camada de mica (de 0,1 e 0,5 cm, respectivamente), que separa os pacotes basal e de topo, e pelo papel lixa sobre a porção posterior do experimento FBF-2b.

A principal diferença na deformação do modelo FBF-2b em relação ao modelo FBF-2a diz respeito à redução do número de falhas produzidas no pós-país e ao papel da camada de mica no interior do sistema acamadado.

Após $25 \%(10 \mathrm{~cm})$ de encurtamento formaram-se no modelo FBF$2 \mathrm{~b}$ apenas três rampas de empurrão (e um retroempurrão) (Fig. 10B). Observam-se além destas rampas, mais duas falhas horizontais: o descolamento basal (falha 4), de pequena extensão, e, no interior da camada de mica, a falha 5. A falha 3 assume o papel da falha 4 do experimento anterior. $\mathrm{Na}$ foto da figura $10 \mathrm{C}$ (após $45 \%$ de encurtamento) registra-se que a falha 5 , no interior da camada de mica, contribuiu muito mais para a acomodação do encurtamento progressivo $(4 \mathrm{~cm})$ do que falha similar no modelo FBF-2a (falha 6). Este fato decorre da maior resistência imposta ao movimento sobre a falha 4 . A foto da figura 10D (com encurtamento de $60 \%$ ) revela a propagação da falha 4 ao longo de rampa e patamar da cunha de madeira. $\mathrm{O}$ movimento subsequente do bloco do teto da falha 4 é acomodado ao longo de parte da falha 5 , preexistente, gerando uma dobra de arrasto. 

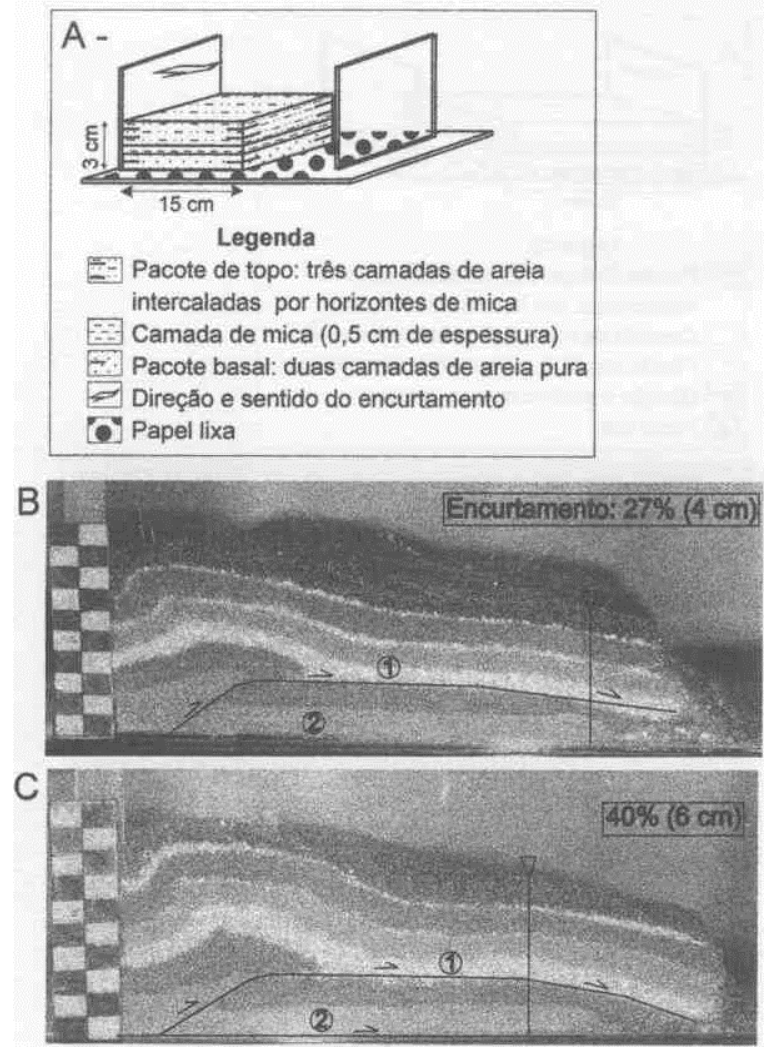

Figura 7 - (A) Desenho esquemático do modelo FBF-1d com as condições de contorno. (B) e (C) Fotografias do modelo após $27 \%(4$ $\mathrm{cm})$ e $40 \%(6 \mathrm{~cm})$ de encurtamento, respectivamente. A escala lateral representa $5 \mathrm{~cm}$. A pin-line nas fotografias representa o comprimento inicial do modelo.

As falhas 4 e 5 ainda não representam uma falha com trajetória em degrau, verdadeira, uma vez que o degrau é formado por segmentos de falhas de diferentes idades.

A análise do sistema compressivo nas figuras 10D e 11 (foto de um corte no interior do experimento FBF-2b) sugere que a alta magnitude de deformação, de $60 \%(24 \mathrm{~cm})$, gerou na realidade uma pilha antiformal. Em uma pilha antiformal as escamas de falhas mais velhas cavalgam os empurrões mais novos, por completo, de maneira que trailing e leading branch Unes coincidem (McClay 1992). Os quatro retroempurrões (l'até 4') (Fig.11) que cortam as falhas 1 e 2 são estruturas que comumente se formam na caixa de experimentos próximo à parede móvel e resultam da rigidez desta (Gomes 1996) sendo bem menos comuns na natureza.

Modelos FBF-2C e 2d Os modelos FBF-2c e 2d (Figs. 12 e 13), de comprimento inicial menor do que aquele dos dois modelos anteriores e com papel lixa sobre toda a extensão da base, simularam falhas com trajetória em degrau. Nestes experimentos, nos quais não se mostrou a deformação progressiva, apenas uma falha se propagou até a superficie de topo do sistema acamadado (a falha 1 , nas duas figuras). A segunda falha (falha 2) se desenvolveu na base da caixa (primeiro patamar), subiu ao longo da rampa da cunha de madeira e prosseguiu sobre o patamar da mesma (segundo patamar). O deslocamento do teto da falha 2 sobre o patamar da cunha de madeira, em detrimento à propagacão do empurrão até a superfície de topo do sistema acamadado, ocorreu em função da presença da camada de mica (neste caso, de $0,1 \mathrm{~cm}$ de espessura) sobre a cunha. Durante o deslocamento, o bloco do teto da falha 2 sofreu deformação gerando uma dobra de arrasto no pacote basal (de areia pura) e uma dobra por deslizamento interestratal, no pacote de topo (de camadas de areia intercaladas por horizontes de mica).

O modelo FBF-2d (Fig. 13), com comprimento inicial igual ao do experimento FBF-2c mas com uma cunha de madeira de ângulo menor $\left(15^{\circ}\right)$, gerou a mesma deformação mas com uma dobra de arrasto de menor amplitude.

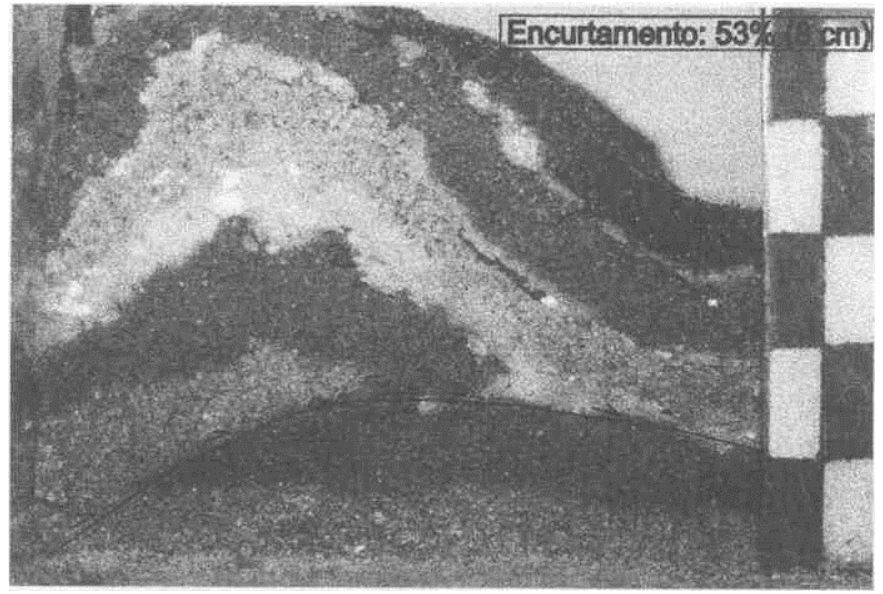

Figura 8 - Uma fotografia ampliada de uma falha em degrau com uma dobra no bloco do teto, após encurtamento de $53 \%(8 \mathrm{~cm})$. O experimento possui as mesmas condições de contorno que o modelo FBF-1d. A escala lateral representa $5 \mathrm{~cm}$.

DISCUSSÃO Em todos os modelos a deformacão se iniciou com o espessamento do sistema acamadado à frente da parede móvel da caixa do experimento seguido pela formação de um descolamento basal e de uma (ou mais) falhas de empurrão. Observou-se que o número de empurrões produzidos durante a deformação progressiva nos modelos, de 3 a 4,6 cm de espessura, depende do comprimento do experimento, do coeficiente de atrito basal e da presença ou não de um 'obstáculo' no antepaís.

Os experimentos revelaram que uma camada de mica em um modelo de areia, confinado entre as duas paredes frontais da caixa de experimentos, isto é com 'obstáculo' no antepaís (modelo FBF-1 a, Fig. 4), simula comportamento plástico ou fluxo de material. Nos experimentos nos quais não se impôs limites ao deslocamento (todos os outros modelos), a camada de mica assumiu com a deformação progressiva o papel de uma falha horizontal de baixo coeficiente de atrito basal favorecendo a formação de um degrau na trajetória da falha de empurrão.

No experimento FBF-la (Fig. 4), o modelo de $40 \mathrm{~cm}$ de comprimento inicial, com um plano de anisotropia interna (a camada de mica) e sem papel lixa na base, o encurtamento gerou um sistema de empurrões em duplex em um processo de propagação por colapso da lapa, como descrito por Huiqi et al. (1992).

Nos experimentos com papel lixa no fundo da caixa e/ou com a cunha de madeira, a resistência imposta ao deslocamento do pacote basal modificou o processo de falhamento acima referido. Nos modelos FBF-lb, FBF-2a e 2b (Figs. 5, 9 e 10) formaram-se falhas com 'falsa' geometria em degrau e apenas nos modelos FBF-lc e $1 \mathrm{~d}$ (Figs. 6 e 7) e FBF-2c e 2d (Figs. 12 e 13) obteve-se sucesso na simulação das estruturas desejadas.

As falhas com 'falsa' geometria em degrau se formaram quando o bloqueio ao movimento sobre o descolamento basal foi parcial. Isto sucedeu no modelo com a cunha de madeira no antepaís mas sem papel lixa sobre a base da caixa (FBF-2a) e nos experimentos com papel lixa apenas na metade posterior do modelo (FBF-lb e $2 \mathrm{~b}$ ). O bloqueio parcial ao movimento no antepaís, onde o deslocamento continuou mas de forma reduzida, causou a reativação das falhas mais antigas do pós-país. No pós-país deu-se o encurtamento das distâncias entre os diversos branch points (branch Unes) até a sua junção, concomitante a deslocamentos menores sobre as respectivas rampas de empurrão. Observou-se que, quando trailing e leading branch Unes se unem formando uma estrutura única, a acomodação do encurtamento no pós-país atingiu o seu limite máximo. A partir deste momento, a deformação progressiva causa forte pressão a favor do movimento do sistema acamadado sobre o deslocamento basal no antepaís. Da crescente resistência a este movimento resulta a formação de uma falha no interior da camada de mica, de baixo coeficiente de atrito basal. Esta falha, horizontal, ao se propagar do pós-país em direção ao antepaís, 

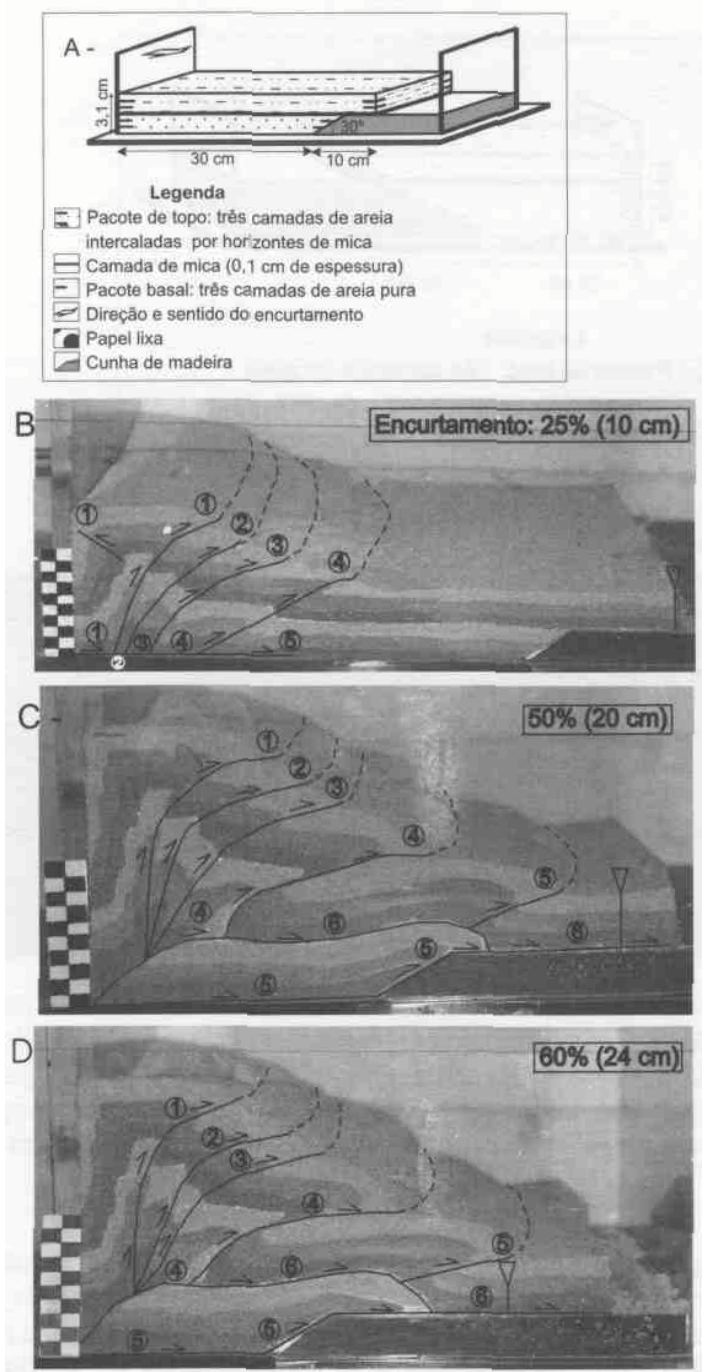

Figura 9 - (A) Desenho esquemático do modelo FBF-2a com as condições de contorno. (B), (C) e (D) Fotografias do modelo após 25\% $(10 \mathrm{~cm}), 50 \%(20 \mathrm{~cm})$ e $60 \%(24 \mathrm{~cm})$ de encurtamento, respectivamente. A escala lateral representa $5 \mathrm{~cm}$. A pin-line nas fotografias representa o comprimento inicial do modelo.

rompe falhas de empurrão previamente formadas (vide figuras 5, 9 e 10; modelos FBF-lb, 2a e 2b).

No modelo FBF-2a (Fig. 9), com a cunha de madeira mas sem papel lixa, o processo acima descrito se observa de maneira mais explícita. Neste modelo, as falhas do pós-país, após a união de três dos seus quatro branch Unes, foram empurradas sobre a falha 4 que, então, se rompeu na altura da camada de mica. Na camada de mica foi gerada a falha 6, horizontal, que corta a falha 5 no antepaís (Fig. 9C).

O modelo FBF-2b (Fig. 10), com cunha de madeira e papel lixa se diferencia do modelo FBF-2a, sem papel lixa (ambos os experimentos de igual comprimento, de $40 \mathrm{~cm}$ ), pelo número menor de falhas (três em vez de quatro). Em FBF-lb (Fig. 5), de comprimento menor (30 $\mathrm{cm}$ ) e sem a cunha de madeira (que nos modelos da série FBF-2 exerceu uma resistência adicional ao movimento) se observa novamente a formação de quatro falhas. Considerando-se normal que modelos mais longos produzam um número maior de falhas (comparar, por exemplo, o modelo FBF-lb, de $30 \mathrm{~cm}$, com o modelo FBF-ld, de $15 \mathrm{~cm}$ ), o fato acima resulta da maior resistência ao movimento sobre o descolamento basal em FBF-2a e 2b. Assim, sugere-se que a alteração no comprimento dos experimentos influencia menos a deformação do que um aumento na resistência ao movimento sobre o descolamento basal.

Sob alta magnitude de deformação, o processo acima descrito (relativo aos modelos FBF-lb, 2a e 2b) que conduziu à formação de falhas com 'falsa' geometria em degrau, pode gerar um sistema de

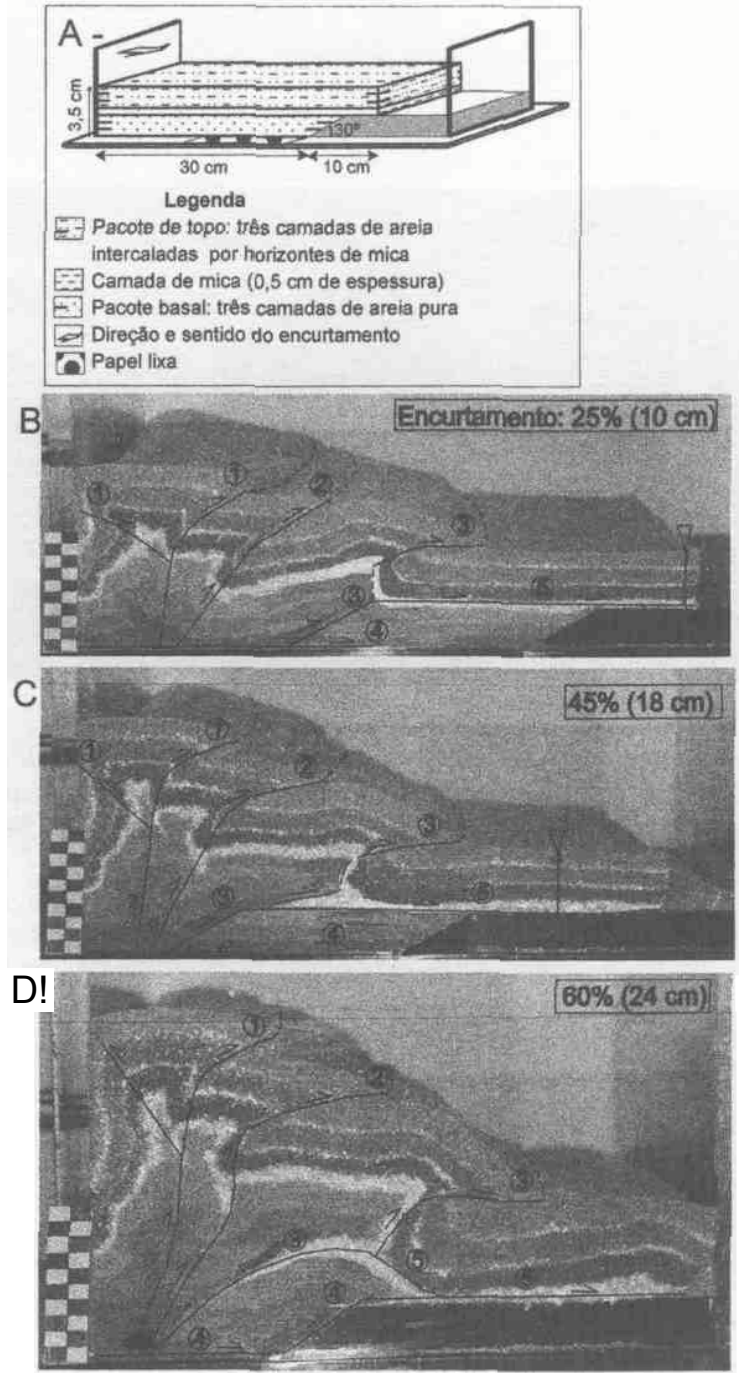

Figura 10 - (A) Desenho esquemático do modelo FBF-2b com as condições de contorno. (B), (C) e (D) Fotografias do modelo após $25 \%$ $(10 \mathrm{~cm}), 45 \%(18 \mathrm{~cm})$ e $60 \%(24 \mathrm{~cm})$ de encurtamento, respectivamente. A escala lateral representa $5 \mathrm{~cm}$. A pin-line vertical nas fotografias representa o comprimento inicial do modelo.

empurrões do tipo pilha antiformal. Este processo ocorre após forte encurtamento quando o antepaís é submetido a uma obstrução total do deslocamento, como já descrito em Gomes \& ferreira (2000).

Os experimentos FBF-lc e $1 \mathrm{~d}$ e FBF-2c e $2 \mathrm{~d}$, mais curtos que os anteriores e com forte resistência ao deslocamento sobre o descolamento basal, geraram as falhas com trajetória em degrau. Nestes modelos formou-se um número reduzido de falhas, apenas uma nos modelos FBF-lc e 1 d (Figs. 6 e 7) e duas, nos modelos FBF-2c e $2 \mathrm{~d}$ (Figs. 12 e 13) e, com a crescente resistência ao deslizamento do pacote acamadado sobre a base da caixa, o encurtamento foi transferido para a camada incompetente de mica, de baixo coeficiente de atrito basal. Ao longo da rampa de empurrão ocorreu no bloco do teto, arrasto e flexão (pacote basal) e dobramento por deslizamento interestratal (pacote de topo).

Em FBF-lc e FBF-ld observa-se que o encurtamento absoluto de $4 \mathrm{~cm}$ (que corresponde a 16 e $27 \%$ de encurtamento relativo, respectivamente) produz resultados qualitativamente iguais e quantitativamente diferentes. O modelo mais curto, de $15 \mathrm{~cm}$ (FBF-ld, Fig. 7) registra uma dobra ampla e de pequena amplitude associada à rampa de empurrão, e também mostra um rejeito de 1,5 a 2,0 cm do teto da falha, além de um pequeno deslocamento do muro desta sobre o descolamento basal. O modelo mais longo, de $25 \mathrm{~cm}$ (FBF-lc, Fig. 6), ilustra uma dobra com geometria em caixa e maior amplitude, associada à rampa de empurrão cujo teto deslocou-se muito pouco ou quase 


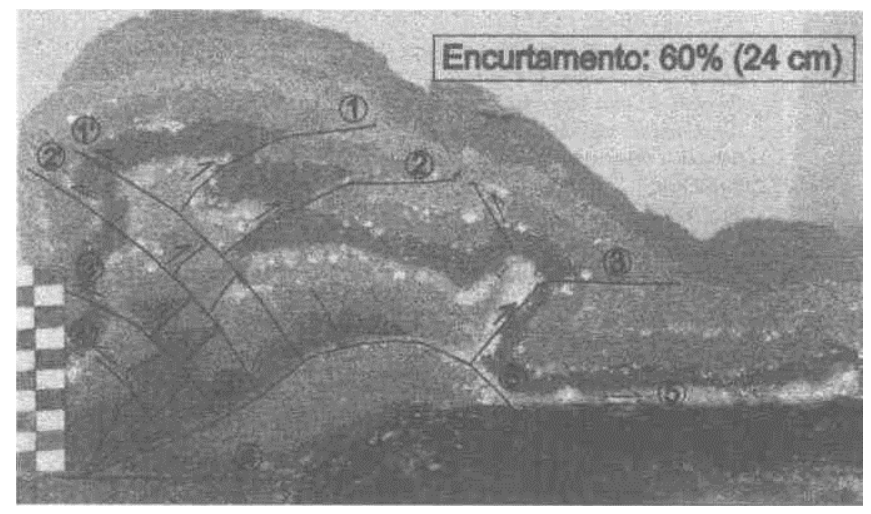

Figura 11 - Fotografia mostrando um corte central no modelo FBF-2b, após $60 \%(24 \mathrm{~cm})$ de encurtamento. A deformação gerou um sistema de empurrões em pilha antiformal. A escala lateral representa $5 \mathrm{~cm}$.
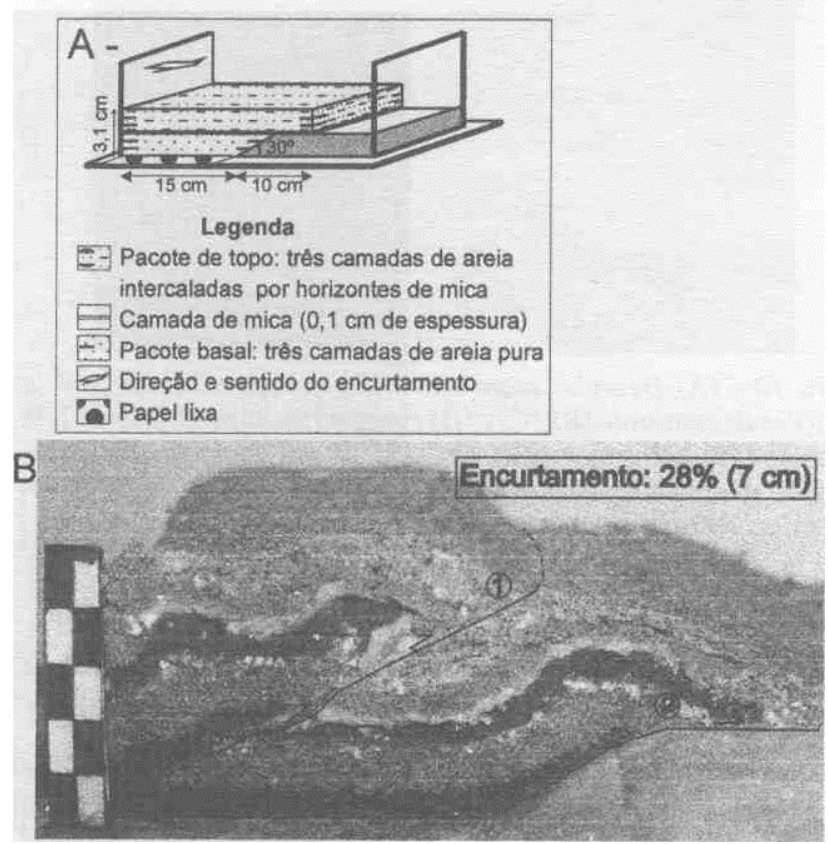

Figura 12 - (A) Desenho esquemático do modelo FBF-2c com as condições de contorno. (B) Fotografia do modelo após $28 \%(7 \mathrm{~cm})$ de encurtamento. Observar a falha com trajetória em degrau sobre a cunha. A escala lateral representa $5 \mathrm{~cm}$.

nada sobre o segundo patamar da falha (falha 1), ao mesmo tempo em que foi nulo o deslocamento do muro desta sobre o descolamento basal. Conclui-se daí que o comprimento do modelo influencia na geometria das estruturas sem, no entanto, alterar o mecanismo de deformação das falhas.

A comparação entre as duas sequências de experimentos (FBF-1 e FBF-2) revela que a introdução da cunha rígida nos modelos da sequência FBF-2, apenas produziu estruturas visualmente mais didáticas. O modelo FBF-2d (Fig. 13) gerou uma dobra de arrasto de pequena amplitude comparada àquela do experimento $\mathrm{FBF}-2 \mathrm{c}$, fato este que

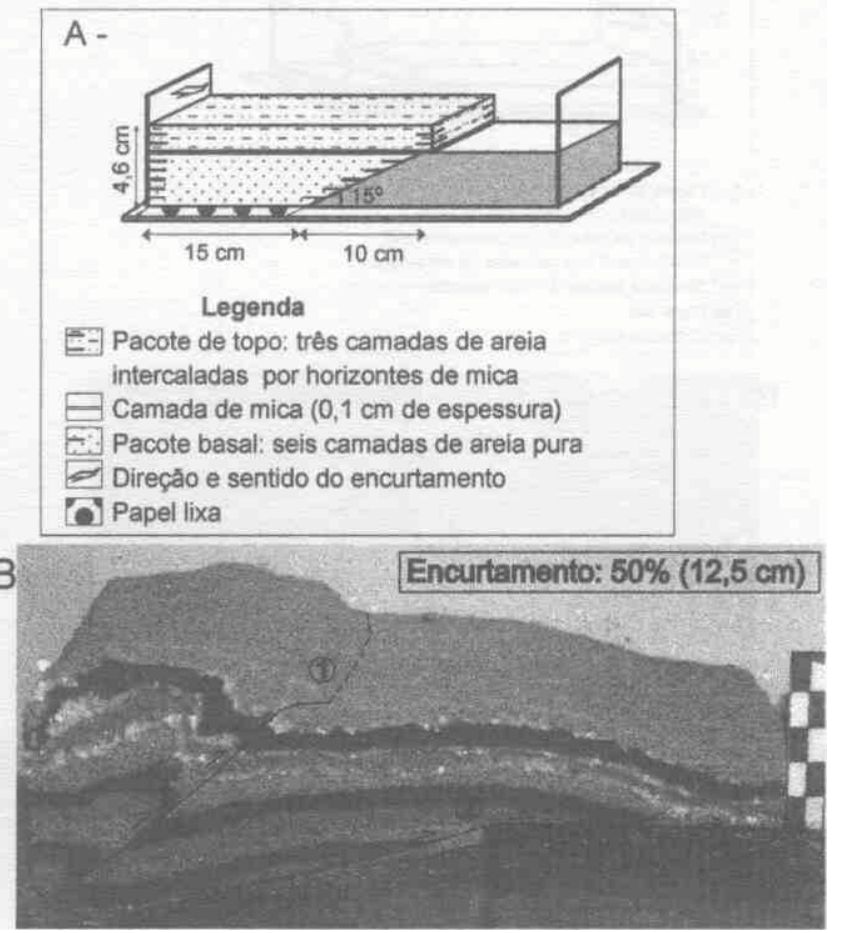

Figura 13 - (A) Desenho esquemático do modelo FBF-2d com as condições de contorno. (B) Fotografia do modelo após $50 \%(12,5 \mathrm{~cm})$ de encurtamento. Observar a falha com trajetória em degrau no antepaís e uma dobra de baixa amplitude causada pelo pequeno ângulo de mergulho da cunha. A escala lateral representa $5 \mathrm{~cm}$.

resultou do baixo ângulo de declividade da cunha $\left(\right.$ de $\left.15^{\circ}\right)$ e que oferece uma resistência menor ao deslocamento do sistema acamadado.

Os experimentos demonstraram que o fator mais importante para a formação de uma falha de empurrão com geometria em degrau não aflorante, em caixas de experimento, é o alto coeficiente de atrito do descolamento basal. Além deste fator, a formação de uma falha em degrau demanda a presença de uma camada incompetente no interior do pacote em deformação (como previsto por Rich 1937). Finalmente, requer ainda o deslocamento livre do pacote situado acima da camada incompetente, isto é nenhum alto estrutural ('obstáculo'), no antepaís, pode interferir no movimento.

A alteração no comprimento dos experimentos não influenciou o mecanismo de deformação causando apenas uma variação na geometria das dobras de arrasto. Os modelos mais longos formaram no teto da falha com trajetória em degrau dobras de arrasto com maior amplitude, o que ocorre em função da maior pressão exercida sobre a rampa do empurrão (compare Figs. 6 e 7).

O efeito da variação na espessura da camada de mica (de $\mathrm{O}, 1,0,5$ e $1,0 \mathrm{~cm}$ ) intercalada entre os pacotes 'basal' (de areia pura) e de 'topo' (de camadas de areia intercaladas por horizontes de cristais de mica) pôde ser considerado nulo.

Os experimentos demonstraram que, em uma deformação por encurtamento, o coeficiente de atrito sobre a base da caixa de experimentos influencia no número de falhas. Quanto maior o coeficiente de atrito, menor será o número de falhas produzidas (comparar modelos FBF-2a e 2b).

A interpretação conjunta dos resultados de presentes modelos sugere que o bloqueio à propagação de uma rampa de empurrão ao topo de um sistema acamadado resulta de uma combinação crítica entre os coeficientes de atrito basal do descolamento (alta) e da camada incompetente (baixa). Empiricamente, esta relação significa que, quanto maior a resistência ao movimento sobre a falha mestra, menor deverá ser o coeficiente de atrito da camada incompetente, para que se concretize a formação de um degrau não aflorante no traçado da falha. Além disto, quanto menor o coeficiente de atrito basal sobre o descolamento, menor a probabilidade de geração de um degrau na falha. 
Em presentes experimentos não se considerou uma inclinação na superficie de descolamento. Enquanto um descolamento basal horizontal, mantém constante o peso gravitacional, $a_{3}$, mesmo fato não ocorre com uma falha mestra inclinada. Nesta, o peso gravitacional, $a_{3}$, no antepaís, em princípio é menor do que no pós-país onde a espessura do prisma em deformação é maior. No entanto, em um cinturão de cavalgamento do tipo pelicular delgado (thin-skin thrust belt), ambiente tectônico característico das falhas com trajetória em degrau, o mergulho da placa subductante não ultrapassa $5^{\circ}$. Esta pequena variação na inclinação da falha mestra, não pode causar mudanças locais significativas na frente de deformação.

No presente trabalho, não houve a intenção de se estudar o mecanismo de formação das fault-bend folds, apesar de sua íntima relação com as falhas em degrau. $\mathrm{O}$ fato se justifica em função do desconhecimento preciso das propriedades mecânicas das rochas durante a deformação, que constitui um problema que foge ao âmbito da Modelagem Física. Nas simulações realizadas desenvolvem-se, no pacote basal, dobras de arrasto, e, na unidade de topo, dobras por deslizamento interestratal. Futuros estudos, de campo e com materiais analógicos alternativos, deverão esclarecer mais este ponto.

A analogia a ser feita entre os presentes experimentos e a natureza não é simples, apesar do trabalho ter sido desenvolvido consoante os requisitos básicos da modelagem física analógica. Alguns problemas existem pois fatores importantes no estudo da deformação de rochas supracrustais, como a pressão dos fluidos e as propriedades mecânicas das rochas supracrustais durante a deformação, não podem ser simuladas.

$\mathrm{Na}$ literatura tem-se discutido muito sobre a magnitude das tensões, necessárias para deslocar blocos crustais de grandes dimensões. Estas tensões teriam que ser infinitamente grandes se não se considerasse a presença de fluidos no sistema. Rubey \& Hubbert (1959), em um trabalho clássico, demonstram que a pressão dos fluidos, diminui a tensão cisalhante requerida para causar a ruptura e/ou o deslocamento sobre uma fratura preexistente, permitindo que domínios em compressão sejam transladados por longas distâncias.

Davis et al. (1983) confirmam o estudo acima citado através de um minucioso trabalho de modelagem física e de cálculos matemáticos aplicado ao Cinturão de dobras e falhas do Taiwan. Os autores também sugerem para o descolamento basal de um sistema em duplex na natureza zonas de fraqueza representadas por litologias incompetentes ou por falhas em rochas rúpteis submetidas a altas pressões de fluidos.

Se, na natureza, conforme descrito na literatura, o deslocamento de grandes blocos crustais exige alta pressão dos fluidos sobre o descolamento basal, é possível assumir que esta, ao longo da extensão do empurrão, às vezes de até centenas de quilômetros, não ocorra de maneira homogênea, mas haja variação na sua magnitude. Um decréscimo progressivo na pressão dos poros, sobre a superficie da falha mestra, em um cinturão de dobras e falhas, explicaria a crescente resistência ao deslizamento sobre a base do modelo, apontada acima como um dos principais fatores para a transferência do movimento, do descolamento basal para a camada de propriedades anisotrópicas. Sugere-se, portanto, que uma variação na pressão dos poros na zona do descolamento, em princípio alta, como preconizado entre outros por
Davis (1983) e Rubey \& Hubbert (1959), possa gerar na natureza uma interrupção, pelo menos temporária, no processo de falhamento por colapso da lapa. Neste caso, o encurtamento prossegue com a formação de uma pilha antiformal (Gomes \& Ferreira 2000) ou, na presença de uma camada incompetente intercalada em um pacote competente, com a formação de uma ou mais falhas com trajetória em degrau.

CONCLUSÕES As modelagens demonstraram que a simulação física de falhas com trajetória em degrau não aflorantes, exige, em caixas de areia, condições especiais. A interpretação dos resultados e a analogia com o sistema natural sugere, entretanto, que, na natureza, as condições para a formação de referidas estruturas é coerente com o quadro complexo normalmente encontrado em cinturões de dobras e falhas.

Durante o processo de encurtamento, nos experimentos, o sistema acamadado de areia, se desloca sobre uma superfície de descolamento, de alto coeficiente de atrito basal, sofrendo progressiva resistência ao movimento. Urna rampa de empurrão se propaga até uma camada incompetente cujo baixo coeficiente de atrito favorece o desvio do movimento para o plano de anisotropia, horizontal. No teto da falha forma-se, no pacote basal uma dobra de arrasto e, no pacote de topo, elasto-plástico, uma dobra por deslizamento interestratal.

Os experimentos desenvolvidos demonstraram que os principais fatores para a formação de uma falha de empurrão com trajetória em degrau não aflorante, são:

- Alto coeficiente de atrito sobre o descolamento basal (ou, presença de um obstáculo do tipo alto estrutural do embasamento) que progressivamente bloqueia a nucleação de novos empurrões no antepaís. Durante o processo de encurtamento, na natureza, uma variação na pressão dos fluidos sobre a falha mestra pode ser considerada normal e esta, quando decresce, gera uma resistência cada vez maior ao deslocamento.

- Presença de uma camada incompetente intercalada entre dois pacotes competentes.

- Baixo coeficiente de atrito da camada incompetente.

- Uma relação crítica entre o coeficiente de atrito do descolamento basal e da camada incompetente: quanto maior a resistência ao movimento sobre a primeira superficie menor será aquela sobre a segunda.

- Ausência de um alto estrutural no antepaís que possa interferir no deslocamento do pacote rochoso sobreposto à camada incompetente.

Agradecimentos os autores expressam os seus agradecimentos ao CNPq, pela cessão de uma Bolsa de Iniciação Científica (PIC / UFOP) e pela Bolsa de Produtividade em Pesquisa vinculada ao projeto (processo 300487/89-4), à FAPEMIG pelo auxílio financeiro (processo: CEX 908/95) e também cessão de uma Bolsa de Iniciação Científica (processo: CEX 2637/97). A autora também agradece ao Dr. Stephen C. Hook, pelos valiosos comentários que contribuíram para a melhor interpretação dos dados de presente estudo, à colega MSc. Maria Silvia C. Barbosa pela criteriosa leitura do trabalho e finalmente aos revisores anónimos pelas sugestões críticas que em muito enriqueceram o artigo.

\section{Referências}

Alkmim F. F. \& Marschak S. 1998. Transamazonian Orogeny in the Southern São Francisco Craton Region, Minas Gerais, Brazil: evidence for Paleoproterozoic collisin and collapse in the Quadrilátero Ferrífero. Precambrian Research, 90:29-58.

Alvarez-Marron J. 1995. Three-dimensional geometry andinterference of fault-bendfolds: examples from the Ponga Unit, Variscan Belt, NW Spain. /. Struct. Geology, 17:549-560.

Byerlee J. 1978. Friction on rocks. Pure and Applied Geophysics, 116:615-626.

Byrne D. E., Wang W., Davis M. 1993. Mechanical role of backstops in the growth of forcares. Tectonics, 12:123-144.

Chapman T. J. \& Williams G. D. 1984. Displacement-distance methods in the analysis of fold-thrust structures and linked-fault systems. J. Geol. Soe. London, 141:121-128.

Chemale Jr. F., Rosière C. A., Endo 1.1991. Evolução tectônica do Quadrilátero Ferrífero, Minas Gerais -Um modelo. Pesquisas, 18:104-127.

CooperM. A, GartonM. R., HossackJ. R. 1983. The origin of the BasseNormandie duplex, Boulonnais, France. J. Struct. Geology 5:|39-152.

Dahlstrom C. D. A. 1969. Balanced cross-sections. Can. Journ. Earth Science, 6:743-757.

Davis D., Suppe J., Dahlen F. A 1983. Mechanics of Fold-and-Thrust Belts and Accretionary Wedges. / Geophys. Research. 88 (B2): 1153-1172.

Dixon J. M. \& Liu S. 1991. Centrifuge modelling of the propagation of thrust faults. In: McClay K.R. (ed.) Thrust Tectonics, Chapman \& Hall, London, 53-70.

Dixon J. M. \& Tirrul R. 1991. Centrifuge modelling of fold-thrust structures in a tripartite stratigraphic sucession. J. Struct. Geology, 13:3-20.
Dorr J. V. N. 1969. Physiographic, stratigraphic and structural development of the Quadrilátero Ferrífero, Brazil. U. S. Geol. Surv. Prof. Paper, 641 (A):110p.; Washington.

Erickson S. G. \& Jamison W. R. 1995. Viscous-plastic finite-element models of fault-bend folds. J. Struct. Geology, 7:561-573.

Evans M.A 1989. The structural geometry and evolution of foreland thrust systems, northern Virgínia. Geol. Soe. Am. Bull., 101:339-354.

Gomes C. J. S. 1996.0 papel do anteparo na modelagem física de cinturões compressivos - um estudo aplicado a um duplex do tipo pilha antiformal. Geonomos, 4:51-60.

Gomes C. J. S. \& Ferreira, J.E. 2000. Geometry and kinemarics of experimental antiformal stacks. Anais da Academia Brasileira de Ciências, 72(2) (no prelo).

Gomes C. J. S., Rosière C. A., Pereira Filho M. 2000. Modelos físicos do Sistema de Cavalgamento Fundão-Cambotas, no Domínio Da Zona De Cisalhamento das Cambotas, Quadrilátero Ferrífero, Minas Gerais. (Revista Brasileira de Geociências, no prelo)

Godin L., Brown R. L., Hanmer S., Parrish R. 1999. Back folds in the core of the Himalayan orogen: An alternative interpretation. Geology, 27:151 -154.

Handin J. 1966. Strength and Ductility. In: Clark Jr. S.P. (Editor), Handbook of Physical Constants, Geol. Soe. Am.Mem. 97:223 - 289.

Hubbert M.K. 1937. Theory of scale models as applied to the study of geological structures. Geol. Soe. Am. Buli., 48:1459-1520.

Huiqi L, McClay K.R., Powell D. 1992. Physical models of thrust wedges. In: Thrust Tectonics (ed. McClay, Chapman \& Hall; London): 71-81. 
Jamison W. R. 1987. Geometric analysis of fold development in overthrust terranes. Journal Structural Geology, 9:207-219.

Johnson A. M. \& Berger P. 1989. Kinematics of fault-bend folding. In: A M. Johnson C. W. Burnham C. R. Allen and W. Muehlberger (Editors), Richard H. Jahns Memorial Volume. Eng. Geol., 27:181-200.

Liu S. \& Dixon J. M. 1991. Centrifuge modelling of thrust faulting: Structural variation along strike in fold-thrust belts. Tectonophysics, 188:39-62.

Marshak S., Wilkerson M. S., Hsui A. T. 1992. Generation of curved fold-thrust belts: Insight from simple physical and analytical models. In: Thrust Tectonics (ed. McClay, Chapman \& Hall, London): 83-92.

Maekel G. \& Walters J. 1993. Finite-element analysis of thrust tectonics: computer simulation of detachment phase and development of thrust faults. Tectonophysics, 226:167-185.

McClay K.R. \& Ellis P.G. 1987. Analogue models of extensional fault geometries. In: Continental Extensional Tectonics (eds. M. P. Coward J. F., Dewey, P. L. Hancock), Geological Society of London - Special Publication, 28:109-125.

McClay K.R. \& Scott A.D. 1991. Experimental models of hangingwall deformation in ramp-flat listric extensional fault systems. Tectonophysics, 188:85-96.

McClay K. R. 1992. Glossary of thrust tectonics. In: Thrust Tectonics (ed. McClay, Chapman \& Hall; London): 419-433.

Mulugeta G. \& Koyi H. 1992. Episodic accretion and partitioning in a model sand wedge. Tectonophysics, 202:319-333.
Ranalli G. 1987. Rheology ofthe Earth: deformation andflow process in geophysics and geodynamics.Allen \& Unwin, Boston, 366p.

Rich J. L. 1934. Mechanics of low-angle overthrust faulting illustrated by Cumberland thrust block, Virgínia, Kentucky and Tennesse. Am. Ass. Petr. Geol., 18:1584-1596

Rubey W. W. \& Hubbert M. K. 1959. Role of fluid pressure in mechanics of overthrust faulting. Geol. Soe. Am. Bull., 70:167-206.

Suppe J. 1983. Geometry and kinematics of fault-bend folding. American Journal of Science, 283:684-721.

Shaw J. H., Hook S. C., Suppe J. 1994. Structural Trend Analysis by Axial Surface Mapping. AAPG Bulletin 78:700 - 721.

Storti F., Salvini F., McClay K. 1997. Fault-related in sandbox analogue models of thrust wedges. Journal Structural Geology, 19:583-602.

Thorbjornsen K. L. \& Dunne W. D. 1997. Origin of a thrust-related fold: geometric vs kinematic tests. Journal Structural Geology, 19:303-319.

Vendeville B., Cobbold P.R., Davy P., Brun J.P., Choukroune P. 1987. Physical models of extensional tectonics at various scales. In: Continental Extensional Tectonics, (Eds. M. P. Coward J. F. Dewey \& Hancock) Geological Society of London, Special Publication, 28:95-107.

Manuscrito A-1073

Recebido em 22 de fevereiro de 1999 Revisão dos autores em 10 de outubro de 1999 Revisão aceita em 15 de outubro de 1999 